\title{
Patterns and factors associated with complications of laparotomy for firearm and blast injuries in the Emergency Management Centre in Erbil city
}

\begin{tabular}{ccc}
\hline Hussen I brahim Taha $^{1}$ & Rawand Musheer Haweizy $^{1 *}$ & ${\text { Sideeq Sadir } \text { Ali }^{2}}^{2}$ \\
\hline Abstract
\end{tabular}

Background and objective: Laparotomy is the surgical opening of the abdomen and the important way to control and treat any problem and complication along pathway site of penetrating by a bullet or shell. This study aimed to identify the patterns and the factors associated with complications of laparotomy for firearm and blast injuries in Erbil City.

Methods: This retrospective study was carried out on 125 injured patients at the Emergency Management Centre in Erbil city. Data was collected from the Statistics Department of Emergency Management Centre from $1^{\text {st }}$ January 2014 to $31^{\text {st }}$ December 2016.

Results: The mean age of the included patients was $26.2 \pm 11.0$. The majority of patients were young $(54.4 \%)$, male $(80 \%)$, lived in the Erbil center $(45.6 \%)$, and the injured place was mostly in the center of Erbil (45.6\%). The mean and standard deviation time needed to arrive at the hospital was $8.7 \pm 39.2$ hours. Most of them had a medium condition $(53.6 \%)$, arrived within the first hour to the hospital (57.6\%), had the first operation at the Emergency Management Centre (89.6\%), did not have any other injury (64\%) and had bullet injuries (88\%). The post operative complications from laparotomy were significantly higher in those with poor condition at admission $(P<0.001)$, not having the first operation at Emergency Management Centre $(P=0.003)$ and higher number of internal organs injured $(P=0.010)$. There was a significant association between postoperative complications from laparotomy with the time needed to arrive at the hospital $(P=0.028)$ and having associated injuries $(P=0.028)$.

Conclusion: Bullet injury was the most common penetrating abdominal trauma leading to one or more intra-abdominal organ injury and needing emergency laparotomy for treatment and prevention of complications. Postoperative complications from laparotomy were significantly associated with the condition of admission, the first operation of the Emergency Management Centre, the number of internal organs injured, the time needed to arrive at the hospital and presence of associated injuries.

Keywords: Patterns; Complications; Laparotomy; Firearm; Blast injury.

\section{Introduction}

Laparotomy is a surgical incision into the abdominal cavity. ${ }^{1}$ Penetrating wounds result from sharp object, bullets or shell injury or knives they might lead to severe hemorrhage, severe disturbances of various organ functions and shock during major internal bleeding. ${ }^{2,3}$ A bullet can lead to damage at the site of penetration and along its pathway. ${ }^{4}$ During emergency situations, abdominal injury such as bullet injury might need exploratory surgery to determine the extent of intra-abdominal bleeding. ${ }^{5}$ Kumar et al. reported in their study; Bullet injury is a leading cause of morbidity and mortality worldwide. When neglected, intra-abdominal injuries and concealed hemorrhage can lead to increased morbidity and mortality, particularly in the patients who might survive the initial phase after an injury. ${ }^{6}$ A retrospective study conducted by

${ }^{1}$ Department of Surgery, College of Medicine, Hawler Medical University, Erbil, I raq.

* Correspondence: rawand_haweizy@yahoo.com 
Duchesne et al. in the United States; reported a total of 196 patients with a bullet and penetrating injuries who underwent damage control laparotomy. A total of 124 $(63.2 \%)$ patients was managed during the laparotomy. ${ }^{7}$ Also, Ball et al. reported in their retrospective study in Canada, during the 10-year study period, 7941 injured adult patients admitted at the Foothills Medical Centre, a total of 151 (2\%) patients was admitted with equestrian injuries, $(7 \%)$ patients died. The average respondent was male $(60 \%)$ and 47 years of age (range, $20-78$ years), with $54 \%$ and $48 \%$ of all patients experiencing chest and head injuries. Overall, 68 of 151 (45\%) patients injured by a horse underwent a surgical procedure. ${ }^{8}$ The incidence of injuries increased substantially during the last few years in Iraq and Kurdistan Region due to the war and insecurity in Iraq. Therefore, this study aimed to identify the patterns and the factors associated with complications of laparotomy for firearm and blast injuries in the Emergency Management Centre during the last three years.

\section{Methods}

\section{Design and setting}

This retrospective study was carried out at the Emergency Management Centre (EMC) in Erbil City. We received those data from the Statistics Department of EMC.

\section{Participants}

Data was collected from the Statistics Department of EMC. We received the information of all patients that were admitted and remained at EMC in Erbil City during the last three years for receiving treatment and discharged between $1^{\text {st }}$ January 2014 and $31^{\text {st }}$ December 2016. A total of 3964 cases of injury were registered at EMC that was admitted and remained at EMC in Erbil City for receiving treatment. Among the 3963 cases of injury that were mentioned above, 3872 cases of them were injured by bullet and shell form deferent part of the body, only 150 cases of them had an abdominal injury, and only 125 cases of the 150 injured patients who had laparotomy at EMC hospital were included in this study.

Tool

A questionnaire consisting of two parts was developed according to the information of the file of the patients. Part 1 included four questions about the socio-demographic characteristics; gender, age, residential area, and place of injury. Part 2 included nine questions about the condition at admission, the time needed to arrive at the hospital, fist operation at EMC, outcome, death or alive, associated injury, postoperative complications from laparotomy and the number of internal organs injured.

\section{Data collection}

Data was collected from the statistical department of EMC through reviewing the file of the patients from $2^{\text {nd }}$ July to $2^{\text {nd }}$ August 2017.

\section{Ethical aspects}

The study protocol was approved by the Research Ethics Committee at the College of Medicine, Hawler Medical University. Institutional permission was obtained from the EMC to getting information from the Statistics Department of EMC.

\section{Data analysis}

Data were analyzed by the statistical package for the social sciences (version 20). Both descriptive and inferential statistics were used. Descriptive statistics involved calculating frequencies and percentages. For inferential statistics, the participants were categorized into those having postoperative complications from laparotomy and not having any complications. The association between the different social-demographic and clinical characteristics with the development of postoperative complications from laparotomy of the participants was assessed using the Chi-square test. A $P$ value of $\leq 0.05$ was considered statistically significant. 


\section{Results}

Table 1 explored the socio-demographic characteristics of the patients. Most patients were young with the age of 18-30 years $(54.4 \%)$. The mean age (SD) of the patients was $26.2 \pm 11.0$ years (range 12-64 years). Most of the patients were male $(80 \%)$ and lived in the center of Erbil city $(45.6 \%)$. Regarding the place of injury, $45.6 \%$ of them were injured in center of Erbil city, $30.4 \%$ from the suburbs of Erbil city (Dashti Hawler, Makhmur), 12.8\% from remote areas of Erbil governorate and $11.2 \%$ from outside of Erbil Governorate.

Table 1: Socio-demographic characteristics.

\begin{tabular}{|c|c|c|c|}
\hline \multirow{2}{*}{ Variable } & & \multicolumn{2}{|c|}{${ }^{*} n=125$} \\
\hline & & $\mathbf{F}$ & $\%$ \\
\hline \multirow{4}{*}{$\begin{array}{l}\text { Age group } \\
\text { (years) }\end{array}$} & $<17$ & 23 & $(18.4)$ \\
\hline & $18-30$ & 68 & $(54.4)$ \\
\hline & $>30$ & 34 & $(27.2)$ \\
\hline & $M \pm S D$ & \multicolumn{2}{|c|}{$26.216 \pm 11.045$} \\
\hline \multirow[t]{2}{*}{ Gender } & Male & 100 & (80) \\
\hline & Female & 25 & $(20)$ \\
\hline \multirow[t]{9}{*}{ Residential area } & Erbil & 57 & $(45.6)$ \\
\hline & Dashti Hawler & 22 & $(17.6)$ \\
\hline & Makhmur & 16 & $(12.8)$ \\
\hline & Outside governorate & 14 & $(11.2)$ \\
\hline & Shaqlawa & 5 & (4) \\
\hline & Koya & 5 & (4) \\
\hline & Soran & 4 & (3.2) \\
\hline & Mergasoor & 1 & $(0.8)$ \\
\hline & Bardarash & 1 & $(0.8)$ \\
\hline \multirow[t]{4}{*}{ Place of injury } & Erbil city & 57 & $(45.6)$ \\
\hline & Erbil city suburbs (Dashti Hawler, Makhmur) & 38 & $(30.4)$ \\
\hline & Erbil remote & 16 & $(12.8)$ \\
\hline & Out of Erbil Governorate & 14 & $(11.2)$ \\
\hline Total & & 125 & $(100)$ \\
\hline
\end{tabular}


Table 2 shows the clinical information and condition of the injured patients. The condition of the majority of the patients at the time of admission was medium (53.6\%). Most patients arrived at the hospital within the first hour (57.6\%). The mean time (SD) needed for arrival at the hospital was $8.7 \pm 39.2$. Majority of the injured patients $(89.6 \%)$ had the first operation in EMC, while only $10.4 \%$ of them had done the first operation at another hospital. Most injured patients did not have any other injury (64\%), but $36 \%$ had another injury in another area of the body. The cause of injury of the majority of patients was bullet injury $(88 \%)$. Most of the sample $(45.6 \%)$ had one internal organ injured, and $28.8 \%$ of them had two internal organs injured. The majority of participants $(61.6 \%)$ did not have any complications from laparotomy. Regarding the end outcome of the patients, $68.8 \%$ had a good health condition, $11.2 \%$ died, $8.8 \%$ remained under follow up (unstable), $5.6 \%$ developed some complications, $4 \%$ left the hospital on their responsibilities, and $1.6 \%$ were transferred to another hospital. Majority of patients $(88.8 \%)$ were alive after laparotomy while $11.2 \%$ died.

Table 2: Clinical characteristics of the injured patients.

\begin{tabular}{|c|c|c|c|}
\hline \multirow{2}{*}{ Variable } & & \multicolumn{2}{|c|}{${ }^{*} \mathrm{n}=125$} \\
\hline & & $\mathbf{F}$ & (\%) \\
\hline \multirow[t]{4}{*}{ Condition at admission } & Missing & 11 & $(8.8)$ \\
\hline & Poor & 26 & (20.8) \\
\hline & Medium & 67 & (53.6) \\
\hline & Good & 21 & (16.8) \\
\hline \multirow[t]{4}{*}{ The time arrived at hospital } & within 1 hour & 72 & $(57.6)$ \\
\hline & 1 - 3 hours & 37 & (29.6) \\
\hline & $>3$ hours & 16 & $(12.8)$ \\
\hline & $M \pm S D$ & \multicolumn{2}{|c|}{$8.7 \pm 39.2$} \\
\hline \multirow[t]{2}{*}{ First operation at EMC } & No & 13 & $(10.4)$ \\
\hline & Yes & 112 & (89.6) \\
\hline \multirow[t]{2}{*}{ Associated injury } & No & 80 & $(64)$ \\
\hline & Yes & 45 & (36) \\
\hline \multirow[t]{2}{*}{ Cause of injury } & Bullet & 110 & (88) \\
\hline & Shell & 15 & $(12)$ \\
\hline \multirow[t]{4}{*}{ Number of internal organs injured } & 0 (Negative) & 8 & $(6.4)$ \\
\hline & 1 & 57 & $(45.6)$ \\
\hline & 2 & 36 & (28.8) \\
\hline & 3 and more & 24 & (19.2) \\
\hline \multirow{2}{*}{$\begin{array}{l}\text { Postoperative complications from } \\
\text { laparotomy }\end{array}$} & No & 77 & (61.6) \\
\hline & Yes & 48 & (38.4) \\
\hline \multirow[t]{6}{*}{ Outcome } & Good health & 86 & $(68.8)$ \\
\hline & Died & 14 & (11.2) \\
\hline & Follow up & 11 & $(8.8)$ \\
\hline & Complications & 7 & (5.6) \\
\hline & Left the hospital on their responsibility & 5 & $(4)$ \\
\hline & Transfer & 2 & $(1.6)$ \\
\hline \multirow[t]{2}{*}{ Death or Alive } & Alive & 111 & (88.8) \\
\hline & Died & 14 & $(11.2)$ \\
\hline
\end{tabular}

${ }^{*}$ Number of samples 
Table 3 shows the association between different demographic and clinical characteristics with the development of postoperative complications from laparotomy. There was a significant association between postoperative complications from laparotomy and the time needed to arrive at hospital (33.3\% for within 1 hours, $35.1 \%$ for 1 - 3 hours, $68.8 \%$ for $>3$ hours, $P=0.028$ ) and associated injury $(51.1 \%$ for yes vs. $31.3 \%$ for no, $P=0.028$ ). A highly significant relationship was found between postoperative complications from laparotomy with the condition at admission
(65.4\% for poor, $35.8 \%$ for medium and $4.8 \%$ for good, $P<0.001$ ), having the 1 st operation at EMC $(76.9 \%$ for no and $33.9 \%$ for yes, $P=0.003$ ). Postoperative complications from laparotomy were significantly higher among those who had three and more internal organs injured, two internal organs injured, one internal organ injured and no any internal organs injured $(62.5 \%, 44.4 \%, 28.1 \%$, and $12.5 \%$, respectively, $P=0.010)$. There was no statistically significant association between the postoperative complications from laparotomy and the other sociodemographic and clinical characteristics.

Table 4: Association between different demographic and clinical characteristics with the development of complications from laparotomy.

\begin{tabular}{|c|c|c|c|c|c|c|c|}
\hline \multirow{3}{*}{ Variable } & & \multicolumn{4}{|c|}{ Complications } & \multirow{3}{*}{ Total } & \multirow{3}{*}{$P$ value } \\
\hline & & \multicolumn{2}{|c|}{ No } & \multicolumn{2}{|c|}{ Yes } & & \\
\hline & & No. & $\%$ & No. & $\%$ & & \\
\hline \multirow{3}{*}{ Age group } & $\leq 17$ & 14 & $(60.9)$ & 9 & (39.1) & 23 & \\
\hline & $18-30$ & 45 & (66.2) & 23 & (33.8) & 68 & 0.431 \\
\hline & $>30$ & 18 & (52.9) & 16 & $(47.1)$ & 34 & \\
\hline \multirow[t]{2}{*}{ Gender } & Male & 62 & $(62)$ & 38 & $(38)$ & 100 & 0.854 \\
\hline & Female & 15 & (60) & 10 & (40) & 25 & \\
\hline \multirow[t]{4}{*}{ Place of injury } & Erbil city & 40 & (70.2) & 17 & $(29.8)$ & 57 & \\
\hline & $\begin{array}{l}\text { Erbil city suburbs (Dashti } \\
\text { Hawler, Makhmur) }\end{array}$ & 22 & $(57.9)$ & 16 & $(42.1)$ & 38 & 0.234 \\
\hline & Erbil remote & 7 & $(43.8)$ & 9 & $(56.3)$ & 16 & \\
\hline & Out of Erbil Governorate & 8 & (57.1) & 6 & (42.9) & 14 & \\
\hline \multirow{3}{*}{$\begin{array}{l}\text { The time arrived at } \\
\text { the hospital }\end{array}$} & within 1 hour & 48 & (66.7) & 24 & (33.3) & 72 & \\
\hline & $1-3$ hours & 24 & (64.9) & 13 & (35.1) & 37 & 0.028 \\
\hline & $>3$ hours & 5 & (31.3) & 11 & $(68.8)$ & 16 & \\
\hline \multirow{2}{*}{$\begin{array}{l}\text { Associated } \\
\text { injury }\end{array}$} & No & 55 & $(68.8)$ & 25 & $(31.3)$ & 80 & 0.028 \\
\hline & Yes & 22 & $(48.9)$ & 23 & (51.1) & 45 & \\
\hline \multirow[t]{2}{*}{ Cause of injury } & Bullet & 70 & (63.6) & 40 & (36.4) & 110 & 0.205 \\
\hline & Shell & 7 & (46.7) & 8 & (53.3) & 15 & \\
\hline \multirow{3}{*}{$\begin{array}{l}\text { Condition at } \\
\text { admission }\end{array}$} & Poor & 9 & (34.6) & 17 & (65.4) & 26 & \\
\hline & Medium & 43 & (64.2) & 24 & (35.8) & 67 & $<0.001$ \\
\hline & Good & 20 & (95.2) & 1 & $(4.8)$ & 21 & \\
\hline \multirow{2}{*}{$\begin{array}{l}1^{\text {st }} \text { Operation at } \\
\text { EMC }\end{array}$} & No & 3 & (23.1) & 10 & (76.9) & 13 & 0.003 \\
\hline & Yes & 74 & (66.1) & 38 & (33.9) & 112 & \\
\hline \multirow{5}{*}{$\begin{array}{l}\text { Number of internal } \\
\text { organs injured }\end{array}$} & 0 & 7 & (87.5) & 1 & (12.5) & 8 & \\
\hline & 1 & 41 & (71.9) & 16 & (28.1) & 57 & \\
\hline & 2 & 20 & (55.6) & 16 & $(44.4)$ & 36 & 0.010 \\
\hline & 3 and more & 9 & (37.5) & 15 & $(62.5)$ & 24 & \\
\hline & Total & 77 & & 48 & & 125 & \\
\hline
\end{tabular}




\section{Discussion}

Erbil is the capital city of the Kurdistan region and was the chief center for fighting against terrorism, especially at the Daesh war. Most of the countries that fought Daesh started the plan and initiated the war against Daesh with Peshmarga from Erbil. Daesh related war in Iraq was from 2014 to 2017. Our retrospective study provides the incidence and outcomes of laparotomy among injured patients by the bullet and shell trauma in the Emergency Management Centre in Erbil City for the last three years. In most previous studies, the penetrating abdominal trauma by bullet commonly cause the major problem and majority of them need for laparotomy. $3,9-14$ There are four emergency hospitals in Erbil city for receiving and treating emergency patients, but only EMC hospital receive patients complaining of bullet and shell injuries. Majority of the cases were young (18-30 years), and the majority of them were male because of the nature of war in any area involving these type of people. The results of our study are supported by many other studies. ${ }^{3,15-18}$ The majority of the victims were living at Erbil, but the injury occurred around Erbil because the war with the Daesh was primarily in Mosel and around of Erbil and the nearest place to treat the victims was Erbil City. The condition of the most of the victims during admission was medium, which may be due to having most of the cases receiving first aid at the point of injury by the first aid teams. Majority of the injured patients did not have any associated injuries. Our study disagreed with a prospective study involving 68 consecutive cases of bullet trauma to the abdomen that conducted by Kulkarni et al. at Kolhapur, Maharashtra State, India where the majority of the of abdominal bullet trauma had associated injuries. ${ }^{19}$ Our study also disagrees with the routinely and prospectively database study of Hildebrand et al. that showed significant association with primarily extra-abdominal injuries. ${ }^{20}$ In our study, the majority of the injured patients had only one internal organ injured. This result is supported by Abri et al. study from Imam Reza Hospital, Tabriz, Iran where 290 patients $(83.3 \%)$ out of 332 patients with abdominal bullet trauma did not have any damage to any organ. ${ }^{21}$ Another main point that focused in this study was the end outcome of the patients and postoperative complications from laparotomy. Majority of the patients had a good health outcome and did not have any complication. This may be because most of them arrived at the hospital within the first hour. It can also be due to having most of them not having another injury in another part of the body. Another reason may be due to having most of the injured persons having only one internal organ injured. These reasons mentioned above are possibly the main cause of having the majority of the patients alive, and only a few of them died. Our study agrees with the study of Karamercan et al. on 144 abdominal bullet trauma at Ankara, Turkey that revealed an overall mortality rate of only $16 \%$, and the postoperative mortality rate concerning the operated patients was $14.3 \% .^{22}$ The mortality rate in our study agrees with the retrospective study that was conducted by RaviKanth et al. at Karnataka, India on 65 bullet trauma patients where the mortality rate was only $20 \% .{ }^{23}$ However, our study disagrees with the retrospective study conducted by Wang et al. from January 2002 to June 2012, at Taiwan, with most of the penetrating abdominal injury after damage control laparotomy had died. ${ }^{24}$ Regarding complications in our study, the result was supported by the retrospective study of Georgi et al. that conducted on two groups; 133 patients with shell fragment injuries and of 166 patients with bullet injuries. The major postoperative complications that occurred in both group was only $7.5 \%$ and $8.4 \%$ of the patients in Group $A$ and Group B, respectively. ${ }^{25}$ Another fact that appeared in our study was the association between different demographic and clinical characteristics with the development of 
complication from laparotomy. There was no significant relationship between complication and place of injury, which may be due to the majority of our cases inside of Erbil City. The results of our study disagreed with a retrospective study of all trauma patients over the age of 18 years from Suez Canal University Hospital, Ismailia, Egypt that was conducted by Gad et al. that revealed a positive association between abdominal trauma and place of injury. ${ }^{26}$ In our study, a significant relationship was founded between the postoperative complications from laparotomy with the time arrived at the hospital. Our result agrees with the retrospective study of Ertel et al. on 311 consecutive patients with severe abdominal and pelvic trauma after "damage-control" laparotomy at Zurich, Switzerland; in their study, a significant improvement was found between emergency laparotomy of all studied organ functions within a few hours. ${ }^{3}$ It also agrees with the two-year prospective study of abdominal trauma patients who presented to the Accident and Emergency at Bugando Medical Centre Mwanza, Tanzania, that was conducted by Chalya and Mabula and revealed that injuryarrival time significantly influenced the outcome with the length of hospital stay $(P=0.015) .{ }^{27}$ Our study disagrees with the retrospective study of Iflazoglu et al. in Turkey that was conducted on 120 patients over 15 years, which reported no significant difference between developing complications and duration of hospital stay and the elapsed time until surgery. ${ }^{28}$ The postoperative complications from laparotomy were also significantly related to the associated injury, which agrees with the previous study of Karamercan et al., which revealed that abdominal bullet trauma was not associated with significant extra-abdominal injuries. ${ }^{22}$ In our study, postoperative complications from laparotomy were significantly associated with the condition at admission. The result was similar to the study of Costa et al. from Roma, Italy that reported a significant association between the average injury severity score of patients with complications $(P<0.05) .{ }^{12}$ Another fact that appear in this study that the postoperative complications from laparotomy were also significantly higher in those not having the first operation at EMC, which may be because EMC was the familiar hospital at Erbil City for receiving and treating injury cases. The postoperative complications from laparotomy were also significantly higher in those having more internal organs injured. This finding was supported by a previous study conducted by Iflazoglu et al. that reported his complications, mortality, and shock were the most significant factors for the development of the high number of injured organs. Also, the number of injured organs was found to be significantly higher than those in the non-complication cases. ${ }^{28}$

\section{Conclusion}

Abdominal trauma by bullet injury was more common in young aged and male patients. Majority of patients arrived at the EMC within the first hour of injury. The condition of the majority of patients during admission was medium and more than one internal organ was injured, but the outcome of most of them was good. Having postoperative complications from laparotomy was significantly associated with the condition at admission, the number of internal organs injured, the time needed to arrive at the hospital and having associated injury.

\section{Competing interests}

The author declares no competing interests.

\section{References}

1. Timby BK, Smith NE. Introductory medicalsurgical nursing. $10^{\text {th }}$ ed. Philadelphia, Baltimore: Lippincott Williams \& Wilkins Published; 2010. P. 723.

2. Williams LS, Hopper PD. Understanding MedicalSurgical Nursing. $2^{\text {nd }}$ ed. Philadelphia: F.A. Davis Company Published; 2003. P. 179.

3. Ertel W, Oberholzer A, Platz A, Stocker R, Trentz $O$. Incidence and clinical pattern of the 
abdominal compartment syndrome after "damage-control" laparotomy in 311 patients with severe abdominal and/or pelvic trauma. Crit Care Med 2000; 28 (6):1747-53.

4. Brunner HR, Suddarth's. Textbook of MedicalSurgical Nursing. $10^{\text {th }}$ ed. Suzanne C. O'Connell Smeltzer; 2003. P. 560.

5. Cavanaugh BM. Nurse's Manual of Laboratory and Diagnostic Tests. $4^{\text {th }}$ ed. Philadelphia: Davis Company Publishing; 2003. P. 391.

6. Kumar A, Sharm S, Salim M. Spectrum and outcome of blunt trauma Abdomen at Sardar Patel Medical College and PBM \& Associate Group of Hospitals. Sch J App Med Sci 2017; 5 (6A):2078-82.

7. Duchesne JC, Kimonis K, Marr AB, Rennie KV, Wahl G, Joel NE, et al. Damage control resuscitation in combination with damage control Laparotomy: A Survival Advantage J Trauma 2010; 69(1):46-52.

8. Ball CG, Ball JE, Kirkpatrick AW, Mulloy RH. Equestrian injuries: incidence, injury patterns, and risk factors for 10 years of major traumatic injuries. Am J Surg 2007; 193(2007):636-40.

9. Wafaisade A, Lefering R, Bouillon B, Sakka S, Thamm O, Paffrath T, et al. Epidemiology and risk factors of sepsis after multiple trauma: Analysis of 29,829 patients from the Trauma Registry of the German Society for Trauma Surgery. Crit Care Med 2011; 39(4):621-8.

10. Howes N, Walker T, Allorto NL, Oosthuizen GV, Clarke DL. Laparotomy for blunt abdominal trauma in a civilian trauma service. S Afr J Surg 2012; 50(2):30-2.

11. Demetriades $D$, Karaiskakis $M$, Toutouzas $K$, Alo K, Velmahos G, Chan L. Pelvic fractures: epidemiology and predictors of associated abdominal injuries and outcomes. J Am Coll Surg 2002; 195:1-10.

12. Costa G, Tierno SM, Tomassini F, Venturini L, Frezza B, Cancrini G, et al. The epidemiology and clinical evaluation of abdominal trauma. Ann Ital Chir 2010; 81(2):95-102.

13. Maske AN, Deshmukh SN. Traumatic abdominal injuries: our experience at rural tertiary care center. Int Surg J 2016; 3(2):543-8.

14. Chandrasekar, Nagappa V, Sivakumar, JebaKumar J. An Experience with Blunt Injury Abdomen -Retrospective Case Series Study. SMJ 2017; 4(2):23-6.

15. Panchal HA, Ramanuj AM. The study of abdominal trauma: patterns of injury, clinical presentation, organ involvement and associated injury. Int Surg J 2016; 3(3):1392-8.

16. Mehta N, Babu S, Venugopal K. An experience with blunt abdominal trauma: evaluation, management and outcome. Clin and Pract 2014; 4(2):599.

17. Dodia H, Sansiya K. A Study of Penetrating Thoracic and Abdominal Injuries. J Dent Med Sci 2015; 14(8):64-95.
18. Kumar S, Kumar B, Kumar B, Damle S. Comparative Study of Hollow Viscus and Solid Organ Injury in Blunt Trauma Abdomen. J Med Dent Sci Res 2016; 3(10):44-9.

19. Kulkarni S, Kanase V, Kanase N, Varute P. Blunt trauma to abdomen in rural setup: A multiple case study. Int J Sci Study 2015; 3(4):16-9.

20. Hildebrand F, Winkler M, Griensven MV, Probst C, Musahl V, Krettek C, et al. Blunt Abdominal Trauma Requiring Laparotomy: an Analysis of 342 Polytraumatized Patients. Hannover Medical School, Hannover, Germany. Eur J Trauma 2006; 32:430-8.

21. Abri B, Shams-Vahdati S, Paknezhad S, Sepehri -Majd P, Alizadeh S. Blunt abdominal trauma and organ damage and its prognosis. Imam Reza Hospital, Tabriz, Iran. J Anal Res Clin Med 2016; 4(4):228-32.

22. Karamercan A, Yilmaz TU, Karamercan MA, Aytaç B. Blunt abdominal trauma: evaluation of diagnostic options and surgical outcomes. Gazi University, Ankara, Turkey. Ulus Travma Acil Cerrahi Derg 2008; 14(3):205-10.

23. RaviKanth J, Gejji SB, Karthik RC. Our experience in blunt trauma abdomen. Int J Sci and Res (IJSR) 2013; 4(8):6-14.

24. Wang S, Liao C, Fu C, Kang S, Ouyang C, Kuo M. An outcome prediction model for exsanguinating patients with blunt abdominal trauma after damage control laparotomy: a retrospective study. BMC Surgery 2014; 14:24.

25. Georgi BA, Massad M, Obeid M. Ballistic trauma to the abdomen: shell fragments versus bullets. J Trauma PubMed 1991; 31(5):711-5.

26. Gad MA, Saber A, Farrag S, Shams ME, Ellabban GM. Incidence, Patterns, and Factors Predicting Mortality of Abdominal Injuries in Trauma Patients. N Am J Med Sci 2012; 4(3):129 -34 .

27. Chalya PL, Mabula JB. Abdominal trauma experience over a two-year period at a tertiary hospital in northwestern, Tanzania: a prospective review of 396 cases. Tanzania J Health Res 2013; 15(4):230-9.

28. Iflazoglu N, Ureyen O, Oner OZ, Tusat M, Akcal MA. Complications and risk factors for mortality in penetrating abdominal firearm injuries: analysis of 120 cases. Int J Clin Exp Med 2015; 8(4):6154-62. 